\title{
Immunocytochemical Localization of Glucagon and Insulin Cells in Eutropis carinata with Respect to Reproductive Cycle
}

\author{
Vidya R. CHANDAVAR ${ }^{2}$ and Prakash R. NAIK ${ }^{1 *}$ \\ ${ }^{1}$ Endocrinology Laboratory, Department of Studies in Zoology, University of Mysore, Manasagangorti, Mysore 570006, \\ India \\ ${ }^{2}$ Yuvaraja's College, University of Mysore, Mysore 570006, India
}

\begin{abstract}
The pancreas of Eutropis carinata was studied immunocytochemically for the presence and topographic distribution of glucagon and insulin cells during annual reproductive cycles. The study revealed paracrine arrangement of the two types of cells. The immunolocalized pancreatic cells revealed significant differences in mean numbers during different periods of reproduction. The numbers of glucagon-immunoreactive (GIR) and insulin-immunoreactive (IIR) cells were highest during the recrudescent period which corresponded with low serum glucose level. Between the two immunoreactive cells, the GIR cells were predominant. Morphological differences between the two cells were observed by electron microscopy after staining with uranyl acetate and lead citrate. Serum glucose showed that cyclic change was highest during the reproductive period.
\end{abstract}

Keywords endocrine cell, pancreas, serum glucose, reproductive cycle, skink

\section{Introduction}

Eutropis (Mabuya) carinata (Mausfeld and Schmitz, 2003 ) is an insectivorous skink (lizard), endemic to southern Asia. It runs swiftly, usually basks during the winter and shifts to shaded areas during the summer. El-Salhy and Grimelius (1981) made histological and immunohistochemical investigation of the endocrine pancreas of the grass lizard, Mabuya quinquetaeniata (Squamata: Scincidae), and that of the desert lizard, Uromastyx aegyptia (Squamata: Agamidae). In both species, the endocrine pancreas were concentrated in the splenic lobe. There was variation in the distribution of beta and alpha cells in different regions of the pancreas. Rhoten and Hall (1982) examined the differentiation of Islets of Langerhans in the lizard Anolis carolinensis. Their results showed that cytodifferentiation of the anole endocrine pancreas occurs, and postoviposition and immunocytochemical methods can be used to follow an organelle sequence during development. The endocrine

\footnotetext{
* Corresponding author: Prof. Prakash R. NAIK from the Department of Studies in Zoology, University of Mysore, India, with his research focusing on endocrine pancreas of reptiles and medicinal plant extracts on diabetic animal models.

E-mail: prakashrnaik@yahoo.co.in

Received: 4 January 2011 Accepted: 2 April 2011
}

pancreas of the lizard, Podarcis hispanica (Squamata: Lacertidae) consisted of scattered cells or small groups of two to five cells forming islet-like structures (Lopez et al., 1988) and that of Podarcis s. sicula is concentrated more in the splenic than in duodenal region and large clusters are never formed (Putti et al., 1991). The Islets of Langerhans in 11 species of lacertids demonstrated the central core of beta cells and alpha cells at the periphery with the predominance of beta cells (Putti et al., 1992). Della and Putti (1995) reported the distribution and frequency of different endocrine cells in the lacertid pancreas. $\mathrm{Ku}$ and Lee (2004) studied the regional distribution and frequency of the pancreatic endocrine cells in the splenic lobe of the grass lizard, Takydromus wolteri, by immunohistochemistry. The cells were dispersed in the whole pancreatic parenchyma between exocrine acinar cells, or they were also observed as islet like clusters. The frequency of each immunoreactive (IR) endocrine cells was calculated as mean number/total 100 islet cells using automated image analysis process. In addition, the percentage of each IR cell was also calculated.

Most of the earlier studies on the endocrine pancreas of different lizards were confined to identifying different cell types by histology, immunocytochemistry and electron microscopy, while the present investigation was under- 
taken to localize glucagon and insulin cells of pancreas during annual seasonal cycle of reproduction and to find out whether they have any effect on the regulation of plasma glucose level in the skink E. carinata.

\section{Materials and Methods}

2.1 Animals E. carinata were collected from the Manasagangotri campus, Mysore (Latitude: $12^{\circ} 18^{\prime} \mathrm{N}$; Longitude: $76^{\circ} 42^{\prime} \mathrm{E}$; Altitude: $777 \mathrm{~m}$ ). Specimens were maintained in the reptile house in the open and fed Silk Moths (Bombyx mori) ad-libitum. The "Guidelines for Care and Use of Animals in Scientific Research" were followed (Indian National Science Academy, 2000). The animals were studied in the seasonal cycle of reproduction (2007 to 2009) annually (January to December), which is distinguished into three separate periods, namely, regenerative, reproductive and recrudescent. Ten adults of both the sexes of E. carinata weighing 12-30 g were utilized in each period. As the animals were collected from the field it was not possible to determine their age, hence measurements were taken. Animals were injected with sodium pentobarbital ( $50 \mathrm{mg} / \mathrm{kg}$ body weight) intra-peritoneally for recording their body length and weight, and were sacrificed. The length of the animal was measured from snout tip to tail tip. The pancreas was freed, its length measured, weighed and fixed in BouinHollande sublimate (Weesner, 1960) solution for 18-20 h (Nozaki et al., 1988) and processed for light microscopy and immunocytochemistry.

2.2 Serum glucose Simultaneously, blood samples from the carotid artery were collected and centrifuged at $4{ }^{\circ} \mathrm{C}$ and $10000 \mathrm{rpm}$ for 10 minutes. The separated serum of ten active animals (ten samples from each animal) was immediately used for estimation of glucose by enzyme glucose oxidase method of Trinder (1969) as described earlier (Chandavar and Naik, 2004; 2008).

2.3 Histology Paraffin embedded pancreases from each animal was sectioned at $4-5 \mu \mathrm{m}$ in series. Ten to fifteen serial sections were mounted on a slide and every second slide was used for light microscopy. Chrome alum Hematoxylin and Phloxin (CHP) staining method (Gomori, 1941) was employed for light microscopy. The sections were deparaffinised, processed through grades of alcohol, and washed in running water. Sections were then treated with acidified $\mathrm{KMnO}_{4}$ and subsequently decolourised with sodium bisulphite, stained with hematoxyline, differentiated in $1 \%$ acidified water, counter stained in phloxin for few minutes and mordant in phosphotungstic acid. CHP stained sections were used for islet measurement at their longest axis at $400 \mathrm{X}$. The size of islet was calculated by random selection of 100 observations in each period $(\mathrm{Ku}$ and Lee, 2004; Weesner, 1960), using the software Image Pro Express, Version 5.1 (Media Cybernetics).

2.4 Immunocytochemistry All the chemicals used in immunocytochemistry were purchased from SigmaAldrich, USA. Every third deparaffinized slide was used for glucagon cell localization and the fourth slide having sections of the same islet was used for insulin cell localization. Insulin cells were immunolocalized by the ExtrAvidin-Biotin Peroxidase method after Yang et al., (1999) and as per the instruction manual provided with the kit. The paraffin embedded sections were deparaffinised, processed through grades of alcohol, washed in running water, pretreated with $3 \% \mathrm{H}_{2} \mathrm{O}_{2}$ in methanol, rinsed with phosphate buffered saline (PBS, $\mathrm{pH} 7.6$ ) and non-specific reactive sites blocked with $5 \%$ normal goat serum. They were then incubated for $1 \mathrm{~h}$ at $37{ }^{\circ} \mathrm{C}$ in a humidified chamber with the respective primary monoclonal mouse antibody (mouse anti-glucagon diluted 1:2000; product No. G2654 and mouse anti-insulin diluted 1:1000; product No. I2018). The sections were carefully washed 10 to 15 times with PBS and incubated for $30 \mathrm{~min}$ with biotinylated goat anti-mouse immunoglobulin secondary antibody and extravidin-peroxidase (Mouse extravidin peroxidase staining kit Stock No. EXTRA-2, Sigma), each diluted 1:20. PBS with 5\% normal goat serum was used as diluent. The peroxidase activity was demonstrated using

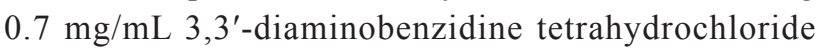
(DAB) in $0.17 \mathrm{mg} / \mathrm{mL}$ urea hydrogen peroxide and 0.06 $\mathrm{mol} / \mathrm{L}$ Tris buffer for 1-3 $\mathrm{min}$. To show that the labeling is specifically due to the primary antibody, the primary antibody is replaced with similarly diluted normal serum from the same species, keeping all the other steps the same in controls (Burry, 2000). Another control for specificity which included omission of primary monoclonal antibody and parallel incubation with antibody reabsorbed with excess of respective antigen. No immunostaining was obtained in the controls. This further confirms that the immunolocalization was specific for islet cells.

The pancreatic sections containing islets were observed throughout the pancreas. Immunoreactive (IR) cell count was done by random selection of 100 sections in every period. Glucagon-IR (GIR) and insulin-IR (IIR) cell counting was done separately by using the software Image Pro Express, Version 5.1 (Media Cybernetics). The total number of GIR and IIR cells of all ten animals in every period was considered as 100 percent, and quantitative analysis in terms of percentage of GIR and IIR cells was calculated. Digital photographs were taken using Olympus 


\section{B x 60.}

2.5 Liver histochemistry Specimens autopsied to collect blood and pancreases were also used for histochemical localization of liver glycogen. Liver was fixed in Rossman's fixative, and then processed, sectioned at 9$10 \mu \mathrm{m}$ and stained following Periodic Acid-Schiff (PAS) technique of Hotchkiss (1968). The PAS positive masses localized in the cytoplasm were taken into consideration for qualitative analysis of glycogen.

2.6 Electron microscopy Pancreases of $0.5 \mathrm{~mm}^{3}$ were fixed for $24 \mathrm{~h}$ at $4{ }^{\circ} \mathrm{C}$ in $3 \%$ glutaraldehyde in $0.1 \mathrm{~mol} / \mathrm{L}$ phosphate (pH 7.2-7.4), and then post fixed in $1 \%$ buffered Osmium tetroxide, en-bloc stained with $2 \%$ uranyl acetate in 95\% ethanol and embedded in Araldite-Cx resin after polymerizing it at $60{ }^{\circ} \mathrm{C}$ for $48 \mathrm{~h}$. Ultrathin sections were obtained with LKB Ultracut microtome, stained with uranyl acetate fallowed by lead citrate, and examined by FM Jeol, EM, electron microscope (Johannessen, 1978).

2.7 Statistical analysis Data from both sexes were pooled together and the measurements were expressed as mean $\pm \mathrm{SD}$ for islet size (in $\mathrm{mm}$ ); cell count (number) and serum glucose level $(\mathrm{mg} / \mathrm{dl})$ during different periods were carried out using analysis of variance (ANOVA). Wherever the ANOVA values $(F)$ were found to be significant, Duncan's Multiple Range Test (DMRT) was applied. The $P$ value $<0.05$ was considered significant.

\section{Results}

Initiation of gonad activity occurred during August and September (Table 1) in both sexes of E. carinata, and this period is designated as the regenerative period, which corresponded with the late monsoon season. Ova and testis were well developed from October to December. This is referred to as reproductive period. Testes in males become smaller and ovaries become smaller in females during recrudescent period, which spans the months of January-July. Different periods of reproductive cycles were assigned by careful observation of the status of the

Table 1 Annual seasonal cycle and reproductive events in $E$. carinata

\begin{tabular}{|c|c|c|c|c|}
\hline & & \multicolumn{3}{|c|}{ Reproductive periods } \\
\hline & & Regenerative & Reproductive & Recrudescent \\
\hline Gonad activity & & Initiation & Peak & Regression \\
\hline Month & & Aug-Sept & Oct-Dec & Jan-July \\
\hline Season & & Late monsoon & Winter & Summer/monsoon \\
\hline \multirow[t]{2}{*}{ Temperature: } & $\max :$ & $31 \pm 2{ }^{\circ} \mathrm{C}$ & $28 \pm 0.5^{\circ} \mathrm{C}$ & $37 \pm 2{ }^{\circ} \mathrm{C}$ \\
\hline & $\min :$ & $19 \pm 0.5^{\circ} \mathrm{C}$ & $13 \pm 2.1{ }^{\circ} \mathrm{C}$ & $18 \pm 2{ }^{\circ} \mathrm{C}$ \\
\hline
\end{tabular}

Note: Specimens were collected during different periods of the years (2007 to 2009). Autopsies were carried out during the months mentioned in the Table and temperatures were recorded. Sample size $n=10$. gonads during the two successive cycles of reproduction.

Weight of the animals varied with the season, being the highest during the regenerative period (Table 2). The mean pancreas weight was the least during this period, while the length of the pancreas was moderate. Reproductive animals weighed minimal, having a higher pancreas weight. During recrudescence, the animals weighed moderately. Significant differences existed between periods with respect to weight of the animal (Table 2). The mean weight of the pancreas during reproductive period was higher and differed significantly from the other two periods. The pancreas on average measured $29.7 \pm 10.28$ $\mathrm{mm}$ in length and weighed $0.18 \pm 0.16 \mathrm{~g}$. Animal length and pancreas length did not differ significantly between the periods.

The islets in E. carinata were irregular without connective tissue capsule. They stained as dark blue clumps of cells surrounded by the lighter stained exocrine pancreas in CHP method, unlike in laboratory mammals (rat). The insulin cells stained darker were round or elongated with central nuclei, but the glucagon cells were not evident in CHP method. Hence, immunocytochemistry was carried out to localize both the cell types. The immunoreactive cells were located in the exocrine pancreas as solitary or two to three cell clusters or as islet throughout the gland (Figure 1. A to F). Smaller clusters were not evident in CHP method. Larger islets exhibited capillary spaces in them and were oriented towards the blood vessel, indicating their endocrine property. This was further confirmed by electron microscopy (EM) (Figure 2. A and B). The endocrine pancreatic cells were found to be distributed along the capillaries. Morphological differences between the two cell types were observed. Under EM the glucagon cells were oval in shape. Their nuclei were placed away from the centre with or without eccentric nucleoli. Cytoplasm showed the presence of dense granules. The secretory granules were round, electron dense and devoid of electron lucent space (Figure 2. B). The insulin cells were elongated or oval in shape with a central round nuclei. The secretory granules were uniformly distributed throughout the cytoplasm. The granules were characteristically membrane bound, filled with dense, rectangular or polymorphic matrix. A distinct electron lucent space between membrane and matrix was prominent (Figure 2. B). There was no significant change in the distribution of islets throughout the pancreas.

During the regenerative period, the islets measured $0.22 \pm 0.09 \mathrm{~mm}$ with lesser count of both GIR $(2645 \pm 32)$ and IIR cells $(2164 \pm 24)$. The plasma glucose was moderate. The regenerative animals exhibited very few PAS positive masses in their liver samples (Table 2).

The animals were found basking during the reproductive period, which corresponded with winter. The pancreas showed the presence of islets in smaller clumps. On average, the islet measured $0.41 \pm 0.24 \mathrm{~mm}$. The GIR 
Table 2 Different stages of reproductive periods and morphometric measurements of E. carinata

\begin{tabular}{|c|c|c|c|c|c|}
\hline \multirow[b]{3}{*}{ Parameters } & \multicolumn{3}{|c|}{ Reproductive periods } & \multirow{2}{*}{\multicolumn{2}{|c|}{ Statistical analysis }} \\
\hline & Regenerative & Reproductive & Recrudescent & & \\
\hline & $($ mean $\pm \mathrm{SD})$ & $($ mean $\pm \mathrm{SD})$ & $($ mean $\pm \mathrm{SD})$ & $F$-value & $P$-value \\
\hline Animal weight (g) & $31.26^{\mathrm{C}} \pm 5.10$ & $17.4^{\mathrm{a}} \pm 4.85$ & $22^{\mathrm{b}} \pm 3.76$ & 23.494 & 0.000 \\
\hline Animal length (mm) & $268.0 \pm 33.2$ & $275.0 \pm 15.8$ & $251.0 \pm 16.5$ & 28.17 & 0.77 \\
\hline Pancreas weight (g) & $0.039^{\mathrm{a}} \pm 0.016$ & $0.461^{\mathrm{b}} \pm 0.44$ & $0.052^{\mathrm{a}} \pm 0.008$ & 8.865 & 0.001 \\
\hline Pancreas length (mm) & $34.8 \pm 13.0$ & $27.5 \pm 13.1$ & $27.0 \pm 0.54$ & 15.45 & 2.32 \\
\hline Plasma glucose (mg/dl\%) & $205^{\mathrm{b}} \pm 57$ & $233^{\mathrm{c}} \pm 47$ & $164^{\mathrm{a}} \pm 25$ & 17.645 & 0.000 \\
\hline Abdominal fat & +++ & $-1+$ & +++ & & \\
\hline Liver glycogen & ++ & $-1+$ & ++ & & \\
\hline
\end{tabular}

Note: Sample size $\mathrm{n}=10$; Mean with the same letters is not significantly different from each other. SD, Standard deviation; +++, Maximum; ++, Moderate; -/+, Minimum.
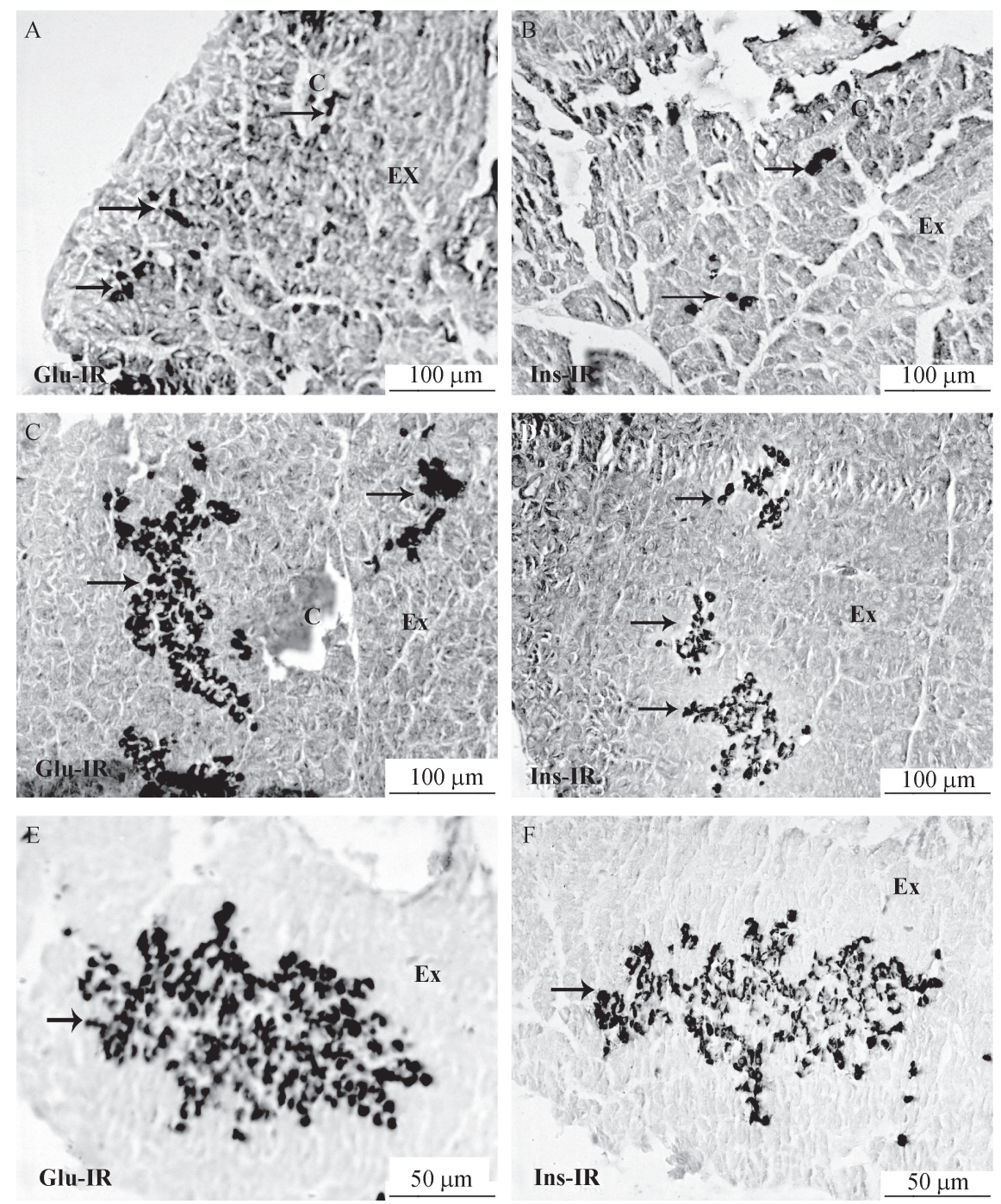

Figure 1 Left top (A). Pancreas of regenerative period shows very few GIR cells appearing dark (arrows) between acini (Ex) and visible blood capillary $(\mathrm{C}) . \times 200$.

Right top (B). Succeeding section of regenerative period shows very few IIR cells appearing dark (arrows) between acini (Ex) and near the blood capillary $(\mathrm{C}) . \times 200$.

Middle left $(\mathbf{C})$. Pancreas of reproductive period shows GIR cells in larger group as dark mass (arrows) between acini (Ex) and blood capillary $(\mathrm{C})$. $\times 200$. Middle right (D). Succeeding section of reproductive period shows darkly stained larger group of IIR cells (arrows) between acini (Ex) than that of the earlier period. $\times 200$.

Bottom left (E). Pancreas of recrudescent period localized for GIR cells which appear as dark mass between acini (Ex). $\times 200$.

Bottom right $(\mathbf{F})$. Succeeding section of recrudescent period shows darkly stained IIR cells (arrow) between acini (Ex). $\times 200$.

Note: All the above photographs are the representatives of each period. 

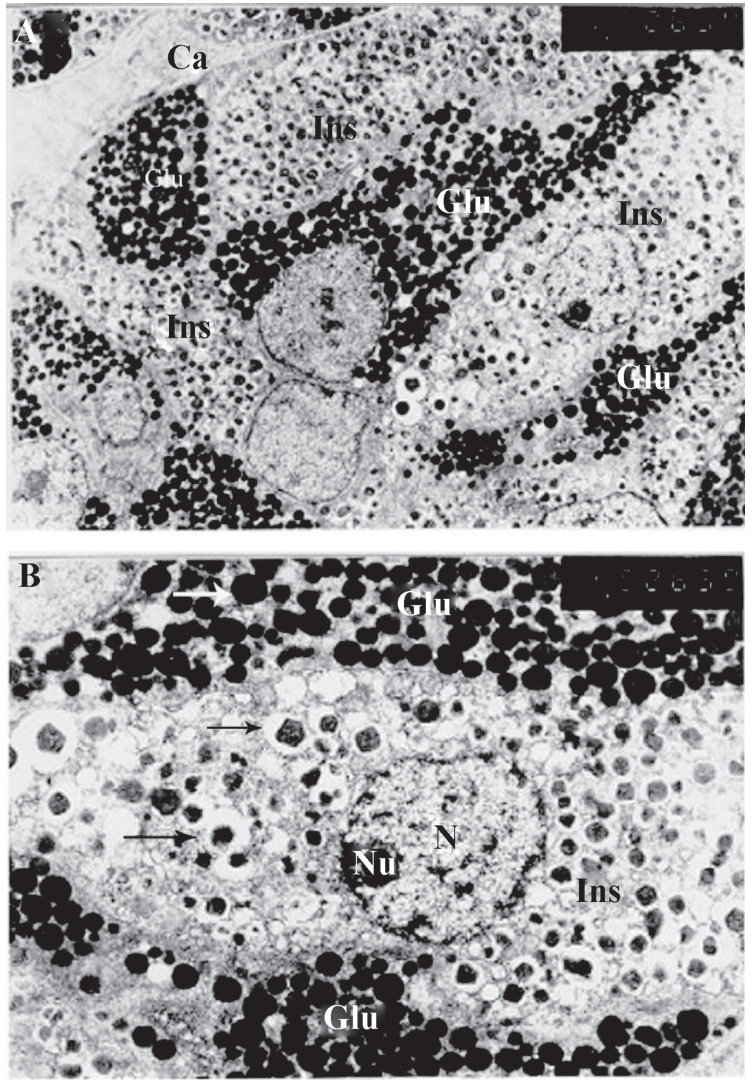

Figure 2 A Electron micrograph of islet region shows glucagon (Glu) cells and insulin (Ins) cells near the blood capillary (Ca). $\times$ 5400 .

Figure 2 B Electron micrograph of an enlarged region of the above islet shows glucagon (Glu) and insulin (Ins) cells with central nucleus $(\mathrm{N})$ and nucleolus $(\mathrm{Nu}) . \times 10000$.

Note: The secretory granules of glucagon cells were electron dense (white arrow) with closely fitting membrane. The secretory granules in insulin cell were prominent with electron lucent space (black arrow) between membrane and matrix.

$(6624 \pm 35)$ and IIR cell $(5425 \pm 36)$ numbers were higher than those during regenerative period. The plasma glucose recorded the highest value. There was no localization of PAS positive masses in liver sections in this period (Table 2).

The maximum numbers of GIR $(9351 \pm 36)$ and IIR (7651 \pm 40$)$ cells were evident during recrudescence. The size of the islet measured $0.69 \pm 0.26 \mathrm{~mm}$. The plasma glucose was the lowest of in all the periods. The liver sections of recrudescent period reveled intensely stained PAS positive masses.

The mean cell count for both-IR cells during recrudescence was the highest and differed significantly from regenerative and reproductive periods, yet the proportion of GIR (55\%) and IIR (45\%) cells remained similar in all the periods with paracrine arrangement being adjacent to one another. This was also evident under electron microscopic studies (Figure 2 A). Significant difference in mean plasma glucose level between periods was observed being highest in reproductive period. The mean size of the islet also showed significant variation between periods being highest in recrudescent period.

\section{Discussion}

Prey consumed by the animals during the regenerative period was converted and stored as reserve food. Conversion of food into fat and muscle mass rendered the animals to weigh higher. The reproductive period appears to be energetically expensive and E. carinata is found to be reliant on stored energy. Therefore, the animals during this period had little abdominal fat and low glycogen mass in their liver. Absence of energy reserve (glycogen and fat) may be due to higher cell count of GIR and IIR cells in comparison to regenerative period. The food consumed by the animals was mainly utilized for the development and maturity of gonads. The reserved food was found diverted to reproduction instead of constructing the body mass, and the animals, on an average weighed the least of all the periods though they were gravid. The decreased liver glycogen may be one of the contributing factors for increasing the plasma glucose during reproductive period which is accompanied by the increased glucagon cells rendering glycogenolysis compared to regenerative period. The phosphorolysis of glycogen is mainly mediated by glucagon (Bollen et al., 1998).

GIR and IIR cells increased from the reproductive period to recrudescent period. The increase in numbers of both cell types may be due to stimulus of higher serum glucose during the reproductive period. Glucose acts as a stimulus to increase in the beta cell numbers (BonnerWeir, 2000). The increased insulin cells in this period, compared to the preceding periods, contributed gradually in building up of liver glycogen and this accounted for the decrease in glucose output. The conversion of glucose into glycogen in liver and availability of glucose to peripheral tissues accompanied by endocrine cells resulted in building up of muscle mass. The increased IIR cells facilitated glucose uptake by peripheral tissue as well as anabolic effect on liver to construct glycogen. As a result the animals weighed more than those in reproductive period with least plasma glucose. The regulation of hepatic glucose metabolism has a key role in whole-body energy metabolism, as the liver is able to store and to produce glucose (Foufelle and Ferré, 2002). Glycogen is stored as a reserve of glucose in liver for extra hepatic tissues. Another glycogenic stimulus for the liver is insulin. As GIR cells were more numerous than IIR cells, the stored energy in the form of abdominal fat was utilized. E. carinata exhibits annual cycle of energy 
storage in the form of abdominal fat.

Due to the cyclic change in plasma glucose, liver glycogen, abdominal fat, and GIR and IIR cell count, $E$. carinata exhibited significant difference in body weight and pancreas weight, but not in body length, which usually remains static for a species.

In the present investigation monoclonal antibodies were used to localize GIR and IIR cells. The use of monoclonal antibodies is the most reliable method for localizing glucagon and insulin cells in pancreas. The most abundant endocrine cell type was GIR cells (55\%). In most of the lizards studied, the endocrine pancreas consists of the central core of beta cells and alpha cells distributed at the periphery, with predominance of beta cells (Putti et al., 1992; El-Salhy et al., 1983). In the pancreas of the reptilian species, IIR cells were present as solitary cells or in groups. They were located in the central core of the pancreatic islets and the most predominant cell type (Morescalchi et al., 1997; PerezTomas et al., 1989). In the present study of E. carinata, very few GIR and IIR cells were scattered or present in smaller groups. In larger islets, GIR and IIR cells were found scattered throughout the islet. This was further confirmed by EM. Insulin containing beta cells or glucagon containing alpha cells were not clustered in the islet as in other lizards (Morescalchi et al., 1997; Putti et al., 1992; Perez-Tomas et al., 1989; El-Sahly et al., 1983), but showed paracrine association with one another. Paracrine interactions might have increased both cell types in number form regenerative to reproductive and from reproductive to recrudescent period. Between the two cell types GIR cells were predominant (55\%) in all the periods. With foregoing studies on lizards, E. carinata appears to be unique.

The normal fasting blood glucose level of five lizard species, namely, Eumeces obsoletus, E. skiltonianus, E. fasciatus, (members of Squamata: Scincidae) Anolis carolinensis, and Sceloporus occidentalis (Squamata: Iguanidae) ranged between $74.0-113.9 \mathrm{mg} / \mathrm{dl}$ as against post-prandial blood glucose level of 142.5-219.7 $\mathrm{mg} / \mathrm{dl}$ (Miller and Wurster, 1956). The highest mean plasma glucose in E. carinata was $233 \mathrm{mg} / \mathrm{dl}$.

Conspicuous variations in the staining property of islets between $E$. carinata and mammals under CHP method reveal that the cytoplasmic granules of glucagon and insulin cells differ from those of mammals. The increase in both the immunoreactive cells occurs together from regenerative to reproductive period, reaching maximum number in recrudescent period. Since the both cell types are lying adjacent to one another, they have marked paracrine effects. Thus, they may affect antagonistically on one another in the regulation of plasma glucose, liver glycogen and abdominal fat in E. carinata.

Acknowledgments The first author acknowledges the University of Mysore for the award of Teacher Fellowship, and the Neuropathology Department of National Institute of Mental Health and Neuro Science, Bangalore for providing the facility to carry out electron microscopy, and the University Grants Commission for the grants provided to carry out immunocytochemical studies. Experimental protocols were approved from Institutional Animal Ethics Committee (IAEC).

\section{References}

Bollen M., Keppens S., Stalmans W. 1998. Specific features of glycogen metabolism in the liver. Biochem J, 336: 19-31

Bonner-Weir S. 2000. Perspective: Postnatal pancreatic $\beta$ cell growth. Endocrinology, 141(6): 1926-1929

Burry R. W. 2000. Specificity controls for immunocytochemical methods. J Histochem Cytochem, 48(2): 163-165

Chandavar V. R., Naik P. R. 2004. Variation in plasma glucose and pancreatic $\beta$ cells in the turtle, Lissemys punctata (Order: Chelonia; Family: Trionychidae). Acta Zool, 85: 113-118

Chandavar V. R., Naik P. R. 2008. Immunocytochemical detection of glucagon and insulin cells in endocrine pancreas and cyclic disparity of plasma glucose in the turtle Melanochelys trijuga. J Biosci, 33: 239-247

Della R., Putti R. 1995. The endocrine pancreas of lacertids: An immunocytochemical study of the genera Pedioplanis and Meroles. Eur J Histochem, 39: 47-58

El-Salhy M., Grimelius L. 1981. Histological and immunohistochemical studies of the endocrine pancreas of lizards. Histochemistry, 72(2): 237-247

El-Salhy M., Abu-Sinna G., Wilander E. 1983. The endocrine pancreas of a squamate reptile, the desert lizard (Chalcides ocellatus). A histological and immunocytochemical investigation. Histochemistry, 78: 391-397

Foufelle F., Ferré P. 2002. New perspectives in the regulation of hepatic glycolytic and lipogenic genes by insulin and glucose: A role for the transcription factor sterol regulatory element binding protein-1c. Biochem J, 366: 377-391

Gomori G. 1941. Observations with differential stains on human islets of Langerhans. Am J Pathol, 17: 395-406

Hotchkiss R. D. 1968. The Periodic Acid Schiff (PAS) Technique. In Pearse A. G. E. (Ed.), Histochemistry Theoretical and Applied. Edinburgh: Churchhill, Living Stone, 659-660

Indian National Science Academy. 2000. Guidelines for care and use of animals in scientific research. New Delhi: Indian National Science Academy, 1-31

Johannessen J. V. 1978. Electron Microscopy in Human Medicine. Vol. 1. Instrumentation Techniques. New York: Mc Graw Hill 
International Book Company, $348 \mathrm{pp}$

Ku S. K., Lee H. S. 2004. The distribution and frequency of endocrine cells in the splenic lobe of grass lizard (Takydromus wolteri). An immunohistochemical study. Eur J Histochem, 48: 429-436

Lopez J. E., Chevarria M., Vazquez J. J. 1988. Histological and immunocytochemical study of the endocrine pancreas of the lizard Podarcis hispanica Steindachner, (Lacertidae). Gen Comp Endocr, 71: 212-228

Mausfeld P., Schmitz A. 2003. Molecular phylogeography, intraspecific variation and speciation of the Asian scincid lizard genus Eutropis, 1843 (Squamata: Reptilia: Scincidae): Taxonomic and biogeographic implications. Org Divers Evol, 3: $161-171$

Miller M. R., Wurster D. H. 1956. Studies on the blood glucose and pancreatic islets of lizards. Endocrinology, 58: 114-120

Morescalchi A. M., Gaccioli M., Faraldi G., Tagliafierro G. 1997. The gastroenteric-pancreatic neuroendocrine system in two reptilian species, Chalcides chalcides and Zoonosaurus madascariensis (Sauridae). Eur J Histochem, 41: 29-40

Nozaki M., Miyata K., Oota Y., Gorbman A., Plisetskaya E. M. 1988. Different cellular distribution of two somatostatins in brain and pancreas of salmonids and their association with insulin and glucagon secreting cells. Gen Comp Endocr, 69: 267-280

Perez-Tomas R., Ballesta J., Pastor L. M., Madrid J. F., Polak J. M. 1989. Comparative immunohistochemical study of the gastroenteropancreatic endocrine system of three reptiles. Gen Comp Endocr, 76: 171-191

Putti R., Varano L., Cavagnuolo A., Laforgia V. 1991. The endocrine pancreas of Podarcis s. sicula Raf.: An immunocytoche mical study at light and electron microscopic levels. Eur J Basic Appl His, 35: 145-159

Putti R., Della Rossa A., Varano L., Laforgia V., Cavagnuolo A. 1992. An immunocytochemical study of the endocrine pancreas in three genera of lacertids. Gen Comp Endocr, 87: 249-259

Rhoten W. B., Hall C. E. 1982. An immunocytochemical study of the cytogenesis of pancreatic endocrine cells in the lizard, Anolis carolinensis. Am J Anat, 163: 181-193

Trinder P. 1969. Determination of blood glucose using oxidase peroxidase system with a non carcinogenic chromogen. J Clin Pathol, 22: 158-161

Weesner F. M. 1960. General Zoological Microtechniques. Calcutta: The Williams and Wilkins Company, 1-230

Yang H., Morrison C. M., Conlon J. M., Laybolt K., Wright J. R. 1999. Immunocytochemical characterization of the pancreatic islet cells of the Nile Tilapia (Oreochromis niloticus). Gen Comp Endocr, 114: 47-56 